DOI: $10.26730 / 1999-4125-2018-2-38-44$

УДК 622.256.753
ОБОСНОВАНИЕ КОНСТРУКЦИИ ПРЕДОХРАНИТЕЛЬНЫХ ПОЛКОВ ПРИ УГЛУБКЕ ВЕРТИКАЛЬНЫХ СТВОЛОВ ШАХТ

\title{
SUBSTANTIATION CONSTRUCTION OF SAFETY SHELVES WITH DEEPENING OF VERTICAL SHAFTS
}

\begin{abstract}
Першин Владимир Викторович, д.т.н., професcop, e-mail: L01BDV @ yandex.ru Vladimir V. Pershin, Dr.-Eng., Prof.

Копытов Александр Иванович, президент Сибирского отделения Академии горных наук, д.т.н., профессор,
\end{abstract} e-mail: L01BDV@yandex.ru Aleksandr I. Kopytov, The president of the Siberian department of the Academy of Mining Sciences, Dr.-Eng., professor Фадеев Юрий Александрович, д.ф-м.н., профессор кафедры математики Yuri A. Fadeev Doctor of Physical and Mathematical Sciences, the professor of the Mathematical Department Вети Ахмед Аиманович, аспирант, e-mail: wetti_a@,mail.ru Akhmed A. Wetti, postgraduate student

Кузбасский государственный технический университет имени Т.Ф. Горбачева, 650000, Россия, г. Кемерово, ул. Весенняя, 28

T.F. Gorbachev Kuzbass State Technical University, 28 street Vesennyaya, Kemerovo, 650000, Russian Federation

Аннотация: На основании проекта реконструкиии Горно-Шорского филиала ОАО «Евразруда», разработанного $A O$ «Гипроруда» для поддержания производственной мощности предприятия 6 млн. тонн в год, ствол «Скиповой» необходимо углубить с отметки +115 м. до отметки -85 м.

В связи с тем, что сроки реконструкиии необходимо было сжать, сотрудниками ООО «СибГорКомплекс Инжиниринг» совместно с кафедрой "Строительство подземных сооружений и иахт» КузГТУ им. Т. Ф. Горбачева были разработаны несколько вариантов новых конструкиий клиновых предохранительныхх полков для углубки вертикальныхх стволов шахт в условиях работы эксплуатачионного подъема.

Анализ отечественного и зарубежного опыта показал, что за последние 30 лет разработкой новых конструкиий предохранительных устройств для углубки вертикальных стволов иахт ни в России, ни за рубежсм никто не занимался, а последние методические указания по их проектированию были разработаны и внедрены еще в 1979 году ВНИИОМШСом и в 1985 году Криворожским горнорудным институтом.

В статье приведены результаты исследований воздействия динамических нагрузок на конструкиию предохранительных устройств при углубке скиповых стволов. На основе методики расчета основных элементов по силовому воздействию при аварийной разгрузке скипов, установлены зависимости позволяющие определить величину динамического воздействия на основные конструктивные элементы предохранительных полков при полном перекрытии сечения ствола, которые могут быть использованы при обосновании параметров конструкции новых клиновых предохранительных полков

Abstract: Based on the reconstruction project the Mountain Shoria branch of OJSC «Evrasruda» developed by JSC "Giproruda" to maintain the production capacity of the enterprise 6 million tons per year "Skipovoy" shaft It is necessary to deepen from the mark $+115 \mathrm{~m}$ to the mark $-85 \mathrm{~m}$.

Due to the time of reconstruction had to be compressed, In this regard, after scientific literature analysis, analysis of existing methods of shafts deepening and types of safety devices analysis, the staff of CUFandM department of T. F. Gorbachev KuzSTU together with specialists from the design organization LLC "Sib- 
GorKompleks Engineering" developed and implemented a new design of protective device for the deepening of vertical shafts in the conditions of operation of the operating lift

Analysis of domestic and foreign experience has shown that over the past 30 years, the development of new designs of safety devices for deepening vertical shafts in Russia, or abroad nobody has and the latest methodological guidelines for their design were developed and implemented in 1979 VNIIOMSHS and in 1985 the Krivoy Rog Mining Institute.

The article presents the results of studies of the effect of dynamic loads on the construction of protective device in the deepening of skip shafts. Based on the methodology for calculating the basic elements for force at emergency unloading of skips, the dependencies allowing to determine the value dynamic impact on the main structural elements of protective device with full overlapping sections of the vertical shaft which can be used when justifying the construction parameters Wedge-type protecting apron

Ключевые слова: вертикальный ствол, углубка, клиновой предохранительный полок, динамическая нагрузка, саморазгрузка скипа.

Key words: vertical shaft, shafts sinking, wedge protective bunton, dynamic load, skips unloading.

Вертикальные стволы и их углубка наиболее важное звено при строительстве и реконструкции горных предприятий, так как только после их завершения появляется возможность выполнять горнопроходческие работы на очередном горизонте по подготовке новых, зачастую более богатых по содержанию полезного компонента, запасов к очистной выемке.

При углубке ствола в процессе эксплуатационного подъема для защиты рабочих в его углубляемой части от возможного падения подъемных сосудов или их содержимого, требуется сооружение предохранительных устройств, которые могут перекрывать все поперечное сечение ствола или же его часть и должны выдерживать огромную ударную нагрузку, а также быть прочными, простыми по конструкции, иметь меньшую трудоемкость при сооружении и последующем демонтаже $[1,2]$.

В каждом конкретном случае конструктивные элементы предохранительного полка, главными из которых являются горизонтальные опорные балки, рассчитываются исходя из назначения и технических условий, принятых для организации работ по углубке ствола.

Анализ опыта углубки вертикальных стволов показывает, что в большинстве проектных решений предлагается использовать искусственные горизонтальные предохранительные полки с опорным элементом из мощных двутавровых балок или ферменных конструкций с полным перекрытием сечения ствола.

Наиболее высокие требования для расчета конструктивных элементов предохранительных полков и их сооружения предъявляются при организации работ при углубке стволов, оснащенных скиповым подъемом. Данный полок должен выдерживать воздействие высоких динамических нагрузок от удара в случае обрыва груженого скипа или просыпи его содержимого, а конструкция обеспечивать возможности сооружения в наиболее короткие сроки с целью сокращения времени остановки эксплуатационного подъема и избежания снижения производительности предприятия
$[3,4]$.

По величине возможной нагрузки на предохранительные полки стволы, оснащенные скиповым подъемом, могут быть:

- с одноканатной подвеской подъемных сосудов;

- с многоканатной подвеской подъемных сосудов;

Для них характерны следующие виды динамического воздействия на полок:

- обрыв груженого скипа;

- аварийная саморазгрузка скипа.

Стволы большинства современных шахт и рудников оснащены мощными подъемными установками с многоканатной подвеской скипов. Одновременный обрыв канатов и падение груженого скипа в данном случае исключен, поэтому предохранительный полок при углубке ствола в условиях работы эксплуатационного подъема постоянно подвергается воздействию отдельно падающих кусков, а также может быть подвержен динамическому воздействию потока горной массы в случае аварийной разгрузки скипа.

Исследования воздействия динамических нагрузок на конструкцию предохранительного устройства позволили установить величины

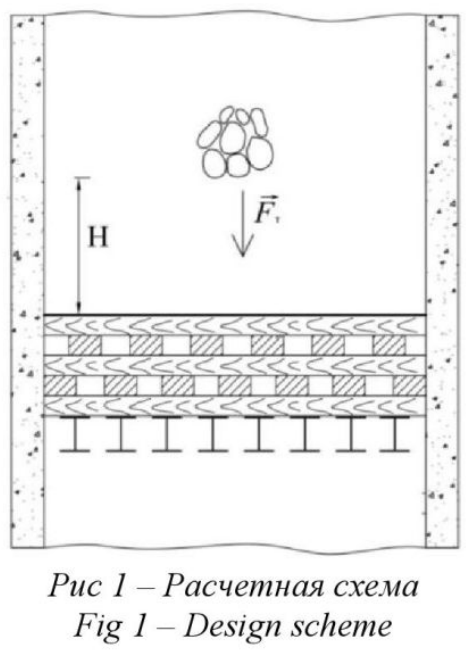

Puс 1 - Расчетная схема
Fig 1 -Design scheme 

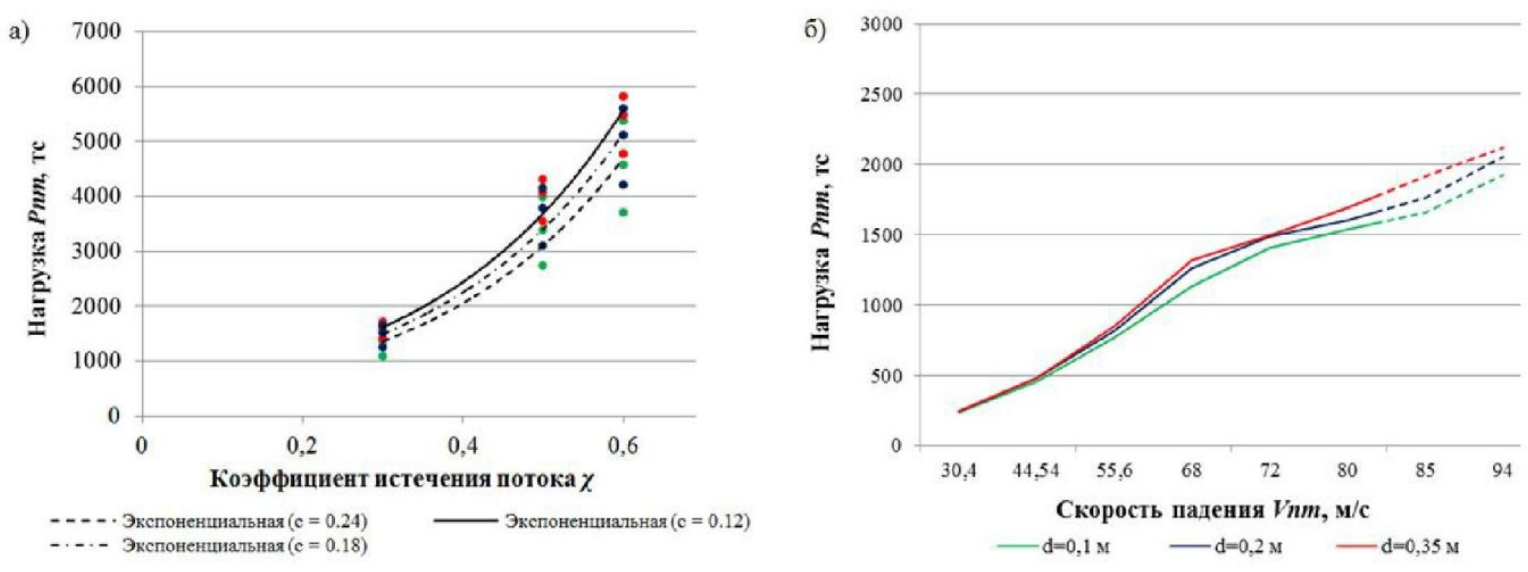

Рис 2 - Зависимость изменения величины силового воздействия $P_{n m}$ от коэффициента истечения потока $\chi_{\text {(а) и от скорости падения }} V_{n m}$ (б) для рудной просыпи разной фракции дробления Fig 2 -Dependence of the change in magnitude of the force action on the flow outflow coefficient $\chi_{\text {(a) }}$ and from the speed of fall $V_{n m}$ (б) for ore spill of different fraction of crushing

a)

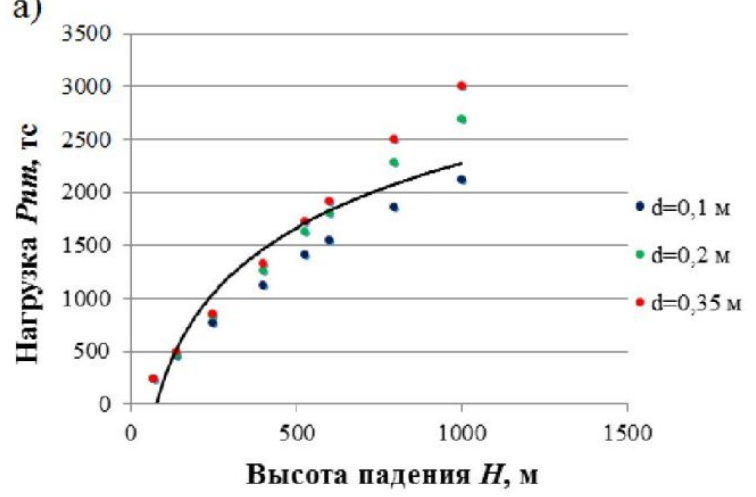

Рис 3 - Зависимость изменения величин нагрузки $P_{n}$ б)

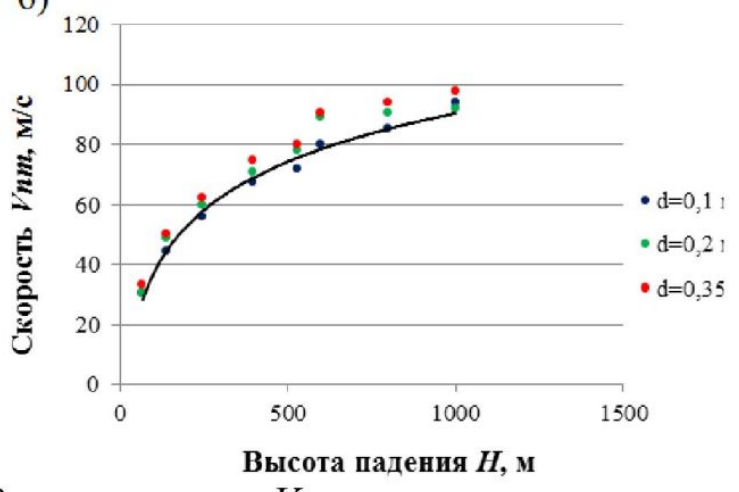

$P_{n m}$ (а) и скорости $V_{n m}$ (б) от высоты падения

Fig 3 -Dependence of changes in load values $P_{n m}$ (a) and speed $V_{n m}$ (б) from height of falling of a solid

нагрузки в зависимости от коэффициента истече-

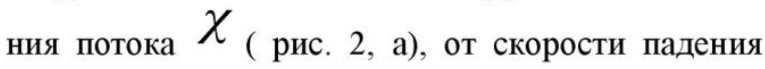
$V_{n m}$ (рис. 2,б) и от высоты падения тела $H$ ( рис. 3, a), а также определить изменение скорости $V_{n m}$ в зависимости от высоты падения тела $H$ ( рис. 3 , б). Принимая во внимание, что скорость воздуха вдали от падающего тела равна нулю, а скорость потока вблизи тела составляет около 100 м/с, можно заключить, что разность давлений по теореме Бернулли будет составлять около 650 кг на квадратный метр. В этом случае, отношение разности давлений к атмосферному давлению будет весьма незначительным ( около 6\%). На основании закона Бойля эта величина характеризует степень сжатия, т.е. при падении тела с такой скоростью можно полагать, что воздух вблизи тела практически несжимаем.
На основании полученных результатов математического моделирования и построенных зависимостей, установлено, что величина силового воздействия на предохранительный полок увеличивается по экспоненте (см. рис. 2, а). В свою очередь, динамическая нагрузка и скорость падения тела возрастают прямо пропорционально в логарифмической зависимости от высоты падения (см. рис.3). Таким образом, изменение значения коэффициента истечения $\chi$, принимаемого в зависимости от фракции дробления, влияет на силу соударения тел о предохранительный полок. Оптимальным размером фракции дробления при этом является величина, не превышающая диаметра 0,2 м.

Расчеты элементов предохранительного устройства с использованием методики определения величины динамических нагрузок в стволе, разработанной для шахт Кривбасса, показывают, что для сплошного перекрытия углубляемой части 
ствола в одном уровне потребуются большие трудозатраты и расход материалов, особенно на сооружение горизонтальных опорных балок.

С целью снижения материальных ресурсов и трудовых затрат при проектировании и сооружении предохранительных полков необходимо учитывать назначение ствола и типоразмеры компоновки оборудования в его сечении.

Так, ствол «Скиповой» в процессе реализации проекта реконструкции Шерегешской шахты Горно-Шорского филиала ОАО «Евразруда» необходимо было углубить с отметки +115 м до отметки -85 м (шаг углубки 200 м).

Ствол предназначен для выдачи руды двумя скипами вместимостью 50 т и двумя скипами для выдачи породы вместимостью 15 т из расчета обеспечения производительности 6 млн. тонн рудной массы в год (рис 4 , а).

Для углубки ствола с горизонта -85 м, который был вскрыт ранее стволом «Ново-Клетевой», в его центральной части буровзрывным способом с использованием комплекса КПВ-2 был пройден восстающий размерами $2 \times 2$ м. Далее работы по углубке ствола выполнялись в направлении сверху вниз полным сечением, с переспуском породы через восстающий на горизонт -85 м и последующей погрузкой в вагонетки ВБ-2,5 с помощью породопогрузочной машины ППМ-2.

Изучение практики сооружения и применения искусственных предохранительных полков при углубке вертикальных стволов шахт показывает, что для принятой технологической схемы возможно использовать элементы конструкции клиновых предохранительных полков, предложенных проф. Федоровым С. А., в которых динамическое воздействие на горизонтальные несущие балки значительно снижается за счет наклонных отражательных стенок [7, 8]. Кроме того, по сравнению с горизонтальными полками, рассчитанными на полное гашение кинетическое энергии, расход материалов в клиновых полках меньше. Учитывая данные преимущества клиновых предохранительных полков, а главное с целью максимального снижения воздействия на них динамических нагрузок, установленных в процессе математического моделирования (рис.2, рис. 3), ООО «СибГорКомплекс Инжиниринг» совместно с кафедрой «Строительство подземных сооружений и шахт» КузГТУ им. Т. Ф. Горбачева были разработаны несколько вариантов новых конструкций клиновых предохранительных полков для углубки вертикальных стволов в условиях работы эксплуатационного подъема, которые защищены патентами на полезные модели $[9,10,11]$. Они представляют собой Z-образную конструкцию из смещенных по высоте и параллельных друг другу верхнего и нижнего предохранительных полков, которые за счет углов наклона выполняют функцию отражательной стенки (рис. 4, б).

На опорных балках, размещенных в основа- нии полков, сооружены буферные распределительно-утяжелительные бетонные плиты и амортизирующие элементы из деревянного бруса, футерованные наклонными отражательными металлическими листами.

Верхняя и нижняя часть предохранительного полка соединены между собой разделительной стенкой, тем самым полностью перекрывая сечение углубляемой части вертикального ствола.

Верхний полок, рассчитанный под большую ударную нагрузку, монтируется под отделением рудных скипов. Под отделением меньших по объему породных скипов сооружается нижняя часть предохранительного полка, рассчитанная на значительно меньшие динамические нагрузки.

Промышленные испытания новой конструкции клинового предохранительного полка, разработанной и рассчитанной с использованием методики влияния силового воздействия на его главный элемент - опорные балки, в случае аварийной саморазгрузки скипа подтвердили ее высокую надежность

Ударная нагрузка в результате неизбежной просыпи рудной массы в объеме до $40 \mathrm{M}^{3}$ в сутки в процессе работы скипового подъема и массой одного куска, достигающей 200 кг в первую очередь воспринимается наклонной плоскостью верхнего предохранительного полка, затем наклонной плоскостью нижнего предохранительного полка, который также воспринимая нагрузку от просыпи скипов породнего подъема. Вследствие изменения направления движения падающих рудных и породных кусков, ударная нагрузка в десятки раз меньше, чем при полном гашении кинетической энергии падающих тел о горизонтальный полок.

Вся просыпь скатывается в специальную отбойную нишу, в качестве которой может использоваться проектная горная выработка из комплекса околоствольных сооружений.

Применение новой конструкции предохранительного полка позволило обеспечить надежную безопасность работ при углубке ствола «Скиповой» Горно-Шорского филиала ОАО «Евразруда», получить экономический эффект в размере 70 млн. рублей за счет снижения расхода материалов, трудоемкости монтажа, демонтажа, и сокращения времени остановки скипового подъема [12, 13, 14].

На основании вышеизложенного можно заключить, что вопрос защиты забоев углубляемых стволов шахт достаточно сложный и важный этап реконструкции горного предприятия. Особенно сложно он решается при углубке скиповых стволов. Сооружение и ликвидация предохранительных полков в условиях действующего ствола, производящего выдачу полезного ископаемого, является трудоемким процессом, требующим детальной увязки работ по защите забоя с эксплуатационной деятельностью шахты. Сложность решения этого вопроса объясняется двумя основными причинами: сооружение предохранительных 
полков в условиях ограниченного времени, выделяемого эксплуатационной службой шахты для остановки скиповых подъемов на период монтажа предохранительных полков, а также большими вероятностными нагрузками, обусловленными возрастающей глубиной отработки месторождения и грузоподъемностью скипов. В связи с этим возникает техническое противоречие: с одной стороны постоянно увеличивающаяся глубина отработки месторождений и грузоподъемность шахтных скипов приводит к необходимости сооружать массивные предохранительные полки, а с другой - сооружение массивных предохранительных полков требует больших затрат времени, что вызывает простой стволов при их монтаже и потери добычи полезных ископаемых. Все это приводит к значительным трудовым, временным и материальным затратам.

Разработанная Z-образная конструкция клинового предохранительного полка и его модификации $[9,10,11]$, включающая смещенные по высоте элементы верхней и нижней частей, футерованных наклонными отражательными листами и соединенные между собой вертикальной разделительной стенкой, позволяет многократно снизить воздействие ударной нагрузки за счет изменения направления движения тела и гашения его кинетической энергии, по сравнению с сооружением массивных, горизонтальных предохранительных полков с полным перекрытием сечения углубляемого вертикального ствола на одном уровне.

Промышленные испытания новой конструкции предохранительного полка при углубке ствола «Скиповой» Горно-Шорского филиала ОАО «Евразруда» подтвердили его высокую надежность, эффективность и безопасность при снижении расхода материалов. Предложенная конструкция позволила снизить материалоемкость и трудоемкость монтажа и демонтажа по сравнению с горизонтальными предохранительными полками. a)

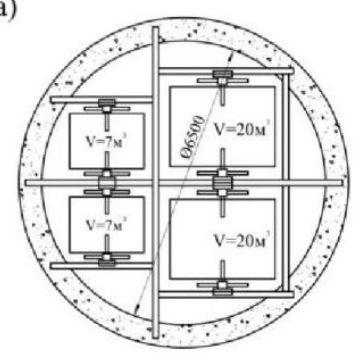

б)

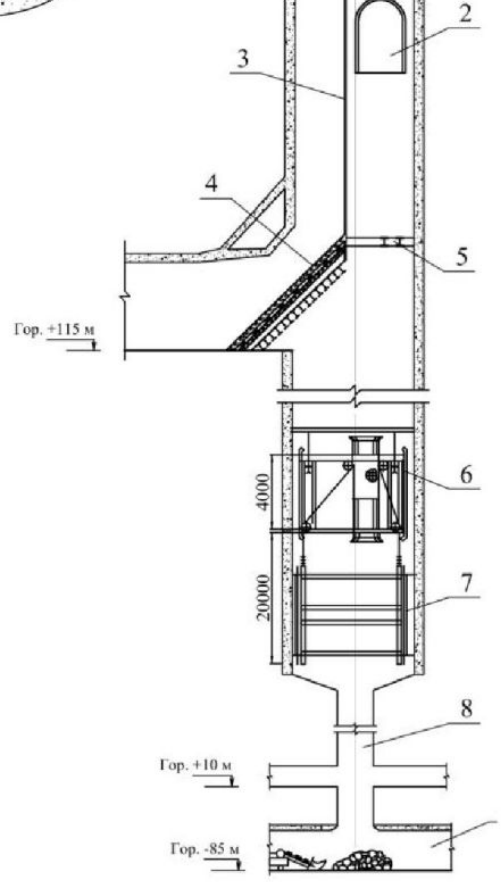

1 - верхний предохранительный полок, 2 - канатный ходок, 3 - разделительная стенка, 4 нижний предохранительный полок, 5 -подшкивная площадка, 6 - подвесной полок, 7 опалубка, 8-восстающий гезенк, 9-подводяшая выработка

Рис 4 - Технологическая схема углубки ствола "Скиповой»

Fig 4-Technological scheme deepening of the "Skipovoy" shaft

\section{СПИСОК ЛИТЕРАТУРЫ}

1. Ковалев В. А. Минерально-сырьевые ресурсы - важный потенциал инновационного развития угольно-металлургического комплекса Кузбасса / В. А. Ковалев, А. И. Копытов, В. В. Першин // Уголь, 2014. - № 2. - С. 6 - 9 .

2. Федеральные нормы и правила в области промышленной безопасности «Правила безопасности в угольных шахтах». Серия 05. Выпуск 40. - Москва : Закрытое акционерное общество «Научнотехнический центр исследования проблем промышленной безопасности», 2014. - 200 с.

3. Единые правила безопасности при разработке рудных, нерудных и россыпных месторождений полезных ископаемых подземным способом : ПБ 03-553-03. Утверждены Постановлением Госгортехнадзора России от 13.05.2003 г., № 30, зарегистрированы Минюстом России 28.05.2003 г, регистрационный № 4600. Серия 03. Выпуск 33/ Москва : ГУП "НТЦ Промышленная безопасность", 2003 - 200 с.

4. Першин, В. В. Строительство и углубка вертикальных стволов шахт: учеб. пособие для вузов / В. В. Першин, А. И. Копытов, В. И. Сарычев. - Новосибирск : Наука, 2014. - 351 с. 
5. Инструкция по расчету, сооружению и ликвидации предохранительных устройств для углубки вертикальных стволов шахт / ВНИИОМШС. - Харьков, 1979. - 91 с.

6. Временная инструкция по защите забоев вертикальных стволов действующих шахт / Минчермет СССР, ВО «Союзшахтопроходка», Криворожский горнорудный институт, Кривой Рог, 1985. - 105 с.

7. Федоров, С. А. Углубка стволов шахт / С. А. Федоров. - Москва : Госгортехиздат, 1963. - 246 с.

8. Смирняков В. В. Технология строительства горных предприятий : Учебник для вузов / В. В.

Смирняков, В. И. Вихарев, В. И. Очкуров. - Москва : Недра, 1989. - 573 с.

9. Патент на полезную модель № 120706 «Клиновой предохранительный полок при углубке вертикальных стволов шахт» Авторы: Копытов А. И., Жук И. В., Войтов М. Д., Морозов С. С. Заявл. 26.04.12 Опубл. 29.07.2012. Бюлл. №27

10. Патент на полезную модель № 133198 «Клиновой предохранительный полок» Авторы: Жук И. В., Копытов А. И., Першин В. В., Войтов М. Д., Вети А. А., Заявл. 06.05.13 Опубл. 10.10.13. Бюлл. №28

11. Патент на полезную модель № 139338 «Клиновой предохранительный полок» Авторы: Копытов А. И., Войтов М. Д., Вети А. А., Заявл. 28.11.2013 Опубл. 14.03.2014. Бюлл. №10

12. Копытов А. И. Новые технологические решения предохранительных устройств для углубки вертикальных стволов шахт / А. И. Копытов, М. Д. Войтов, А. А. Вети // Горный журнал, 2015. - № 1 - С. $67-70$.

13. Pershin V. V. Construction parameters updating of protecting apron under deepening of vertical shafts / V. V. Pershin, A. I. Kopytov, M. D. Voitov, I. V. Zhuk, A. A. Wetti // Taisan Academic Forum - Project on mine Disaster Prevention and Control, 2014. - P. $21-26$.

14. Kopytov A. I. The improvement of the bunton construction of mine-shaft equipment / A. I. Kopytov, V. V. Pershin, M. D. Voitov, A. A. Wetti // The 8 th Russian-Chines symposium coal in 21 st century : mining, processing and safety, $2016-$ P. $108-111$.

\section{REFERENCES}

1. Kovalev V. A. Mineral'no-syr'evye resursy - vazhnyy potentsial innovatsionnogo razvitiya ugol'nometallurgicheskogo kompleksa Kuzbassa / V. A. Kovalev, A. I. Ko-pytov, V. V. Pershin // Ugol', 2014. - № 2. P. 6 - 9 .

2. Federal'nye normy i pravila v oblasti promyshlennoy bezopasnosti «Pravila bezopasnosti v ugol'nykh shakhtakh». Seriya 05 . Vypusk 40. - Moskva : Zakrytoe aktsionernoe obshchestvo «Nauchno-tekhnicheskiy tsentr issledovaniya problem promyshlennoy bezopasnosti», 2014. $-200 \mathrm{p}$.

3. Pershin, V. V. Stroitel'stvo i uglubka vertikal'nykh stvolov shakht: ucheb. po-sobie dlya vuzov / V. V. Pershin, A. I. Kopytov, V. I. Sarychev. - Novosibirsk : Nauka, 2014. - 351 p.

4. Edinye pravila bezopasnosti pri razrabotke rudnyh, nerudnyh i rossypnyh mestorozhdenij poleznyh iskopaemyh podzemnym sposobom : PB 03-553-03. Utverzhdeny Postanovleniem Gosgortekhnadzora Rossii ot 13.05.2003 g., № 30, zaregistrirovany Minyustom Rossii 28.05.2003 g, registracionnyj № 4600. Seriya 03. Vypusk 33/ Moskva : GUP "NTC Promyshlennaya bezopasnost"', 2003 - $200 \mathrm{~s}$.

5. Instruktsiya po raschetu, sooruzheniyu i likvidatsii predokhranitel'nykh ustroystv dlya uglubki vertikal'nykh stvolov shakht / VNIIOMShS. - Khar'kov, 1979. - 91 p.

6. Vremennaya instruktsiya po zashchite zaboev vertikal'nykh stvolov deystvuyushchikh shakht / Minchermet SSSR, VO «Soyuzshakhtoprokhodka», Krivorozhskiy gornorudnyy in-stitut, Krivoy Rog, 1985. - 105 p.

7. Fedorov S. A. Uglubka stvolov shakht / S. A. Fedorov. - Moskva : Gosgorte-khizdat, 1963 - 246 p.

8. Smirnyakov, V. V. Tekhnologiya stroitel'stva gornykh predpriyatiy : Uchebnik dlya vuzov/ V. V. Smirnyakov, V. I. Vikharev, V. I. Ochkurov. - Moskva : Nedra, 1989. - 573 p.

9. Patent na poleznuyu model' № 120706 «Klinovoy predokhranitel'nyy polok pri uglubke vertikal'nykh stvolov shakht» Avtory: Kopytov A. I., Zhuk I. V., Voytov M. D., Morozov S. S. Zayavl. 26.04.12 Opubl. 29.07.2012. Byull. №27

10. Patent na poleznuyu model' № 133198 «Klinovoy predokhranitel'nyy polok» Avtory: Zhuk I. V., Kopytov A. I., Pershin V. V., Voytov M. D., Veti A. A., Zayavl. 06.05.13 Opubl. 10.10.13. Byull. №28

11. Patent na poleznuyu model' № 139338 «Klinovoy predokhranitel'nyy po-lok» Avtory: Kopytov A. I., Voytov M. D., Veti A. A., Zayavl. 28.11.2013 Opubl. 14.03.2014. Byull. №10

12. Kopytov A. I. Novye tekhnologicheskie resheniya predokhranitel'nykh ustroystv dlya uglubki 
vertikal'nykh stvolov shakht / A. I. Kopytov, M. D. Voytov, A. A. Veti // Gornyy zhurnal, 2015. - № 1 - P. 67 70 .

13. Pershin V. V. Construction parameters updating of protecting apron under deep-ening of vertical shafts / V. V. Pershin, A. I. Kopytov, M. D. Voitov, I. V. Zhuk, A. A. Wetti // Taisan Academic Forum - Project on mine Disaster Prevention and Control, 2014. - P. $21-26$.

14. Kopytov A. I. The improvement of the bunton construction of mine-shaft equip-ment / A. I. Kopytov, V. V. Pershin, M. D. Voitov, A. A. Wetti // The 8 th Russian-Chines symposium coal in 21 st century : mining, processing and safety, $2016-$ P. $108-111$. 